\title{
Physical Properties and Compressive Strength of Zinc Oxide Nanopowder as a Potential Dental Amalgam Material
}

\author{
Nanang Qosim ${ }^{1}$, Putut Murdanto ${ }^{2}$, Poppy Puspitasari ${ }^{3}$ \\ ${ }^{1}$ Department of Mechanical Engineering, Faculty of Engineering, Universitas Indonesia, Jawa Barat, Indonesia \\ ${ }^{2,3}$ Department of Mechanical Engineering, Faculty of Engineering, Universitas Negeri Malang, Jawa Timur, Indonesia
}

\begin{abstract}
Article Info
\section{Article history:}

Received Jan 2, 2018

Revised May 12, 2018

Accepted May 27, 2018

\section{Keyword:}

Dental amalgam

Mercury

Nanopowder

$\mathrm{ZnO}$

ABSTRACT

In this study, the application of nanotechnology was applied in the dentistry field, especially in the innovation of dental amalgam material. To date, mercury $(\mathrm{Hg})$ has been used widely as dental amalgam material with consideration of the cheap price, ease of use, and good mechanical strength. However, last few years, many problems have been faced in the dentistry field due to the use of mercury. Hence, new material is needed as an innovation to eliminate the mercury from dental amalgam composition. This research was conducted to analyze the physical properties and compressive strength of zinc oxide $(\mathrm{ZnO})$ nanopowder as a potential dental amalgam material. The physical properties such as morphology and dimensions were analyzed by SEM and XRD. Further, the compression test was conducted by using hydraulic press machine. The results showed that the $\mathrm{ZnO}$ nanopowder analyzed has the particle size of $14.34 \mathrm{~nm}$ with the morphology classified as nanorods type. On the compression load of $500 \mathrm{~kg}$, the average of $\mathrm{ZnO}$ green density is $3.170 \mathrm{~g} / \mathrm{cm} 3$. This value experienced the increase of $4.763 \%$ when the load was set to $1000 \mathrm{~kg}$, and $7.539 \%$ at $2000 \mathrm{~kg}$. The dwelling time also took the same effect. At 30 seconds, the average of $\mathrm{ZnO}$ green density is $3.260 \mathrm{~g} / \mathrm{cm} 3$. This value experienced the increase of $0.583 \%$ at 60 seconds and $3.098 \%$ at 90 seconds.
\end{abstract}

Copyright (C) 2018 Institute of Advanced Engineering and Science. All rights reserved.

\section{Corresponding Author:}

Nanang Qosim,

Department of Mechanical Engineering, Faculty of Engineering,

Universitas Indonesia,

Kampus Baru UI, Depok 16424, Jawa Barat, Indonesia.

Email: nanang.qosim@ui.ac.id

\section{INTRODUCTION}

The use of dental amalgam has been used for more than 150 years as the treatment of cavity filling and is still being used due to its excellent mechanical properties as a method of dental restorations [1]. Dental amalgam is an alloy of mercury (Hg) combined with one or more other metallic elements. There are several types of amalgam alloys, all of which contain tin, copper, and mercury. These alloys are known as amalgam alloys based on ISO (International Organization for Standardization) standard [2].

Last few years many problems have been faced in dentistry field because of the use of mercury in the composition of amalgam material. Any type of mercury is very dangerous in humans because mercury is neurotoxic and will accumulate in the body. The effects of its toxicity on the health of the body include nerve damage, paralysis, blindness, mental disorders, chromosomal damage and infant defects in the womb [2, 3]. On the other hand, the metallic color of this amalgam does not blend with the natural tooth color as shown in Figure 1 left, so patients and professionals preferred tooth-colored restorative material for cavity filling in carious teeth for better aesthetics. 

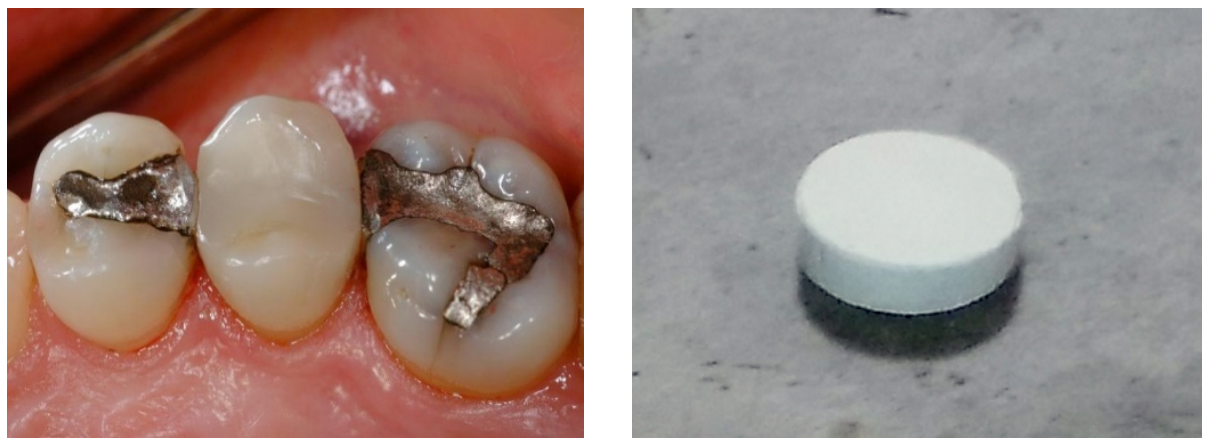

Figure 1. The metallic color of amalgam does not blend with the natural tooth color (left); ZnO nanopowder color resembles the original color of tooth (right)

Zinc Oxide $(\mathrm{ZnO})$ is a unique material widely used by most researchers for a wide range of applications. ZnO has various types of morphology and sizes that will determine the suitability of its use. This material has been commonly used for additives in paints, ceramic materials, catalysts, electronic equipment, optoelectronics, semiconductors and much more. The uniqueness of the $\mathrm{ZnO}$ nanostructure shape shows that $\mathrm{ZnO}$ is the richest material in the nanomaterial family, both in terms of structure and properties. The properties of $\mathrm{ZnO}$ nanopowder depend on the morphological character and its nanostructures determined from the synthesis method used [4, 5]. This excellent combination of characteristics, in addition to $\mathrm{ZnO}$ color that resembles the original color of the tooth as shown in Figure 1. right, is expected to provide an innovation as a potential amalgam material to eliminate mercury compositions.

\section{METHODS}

\subsection{Physical Properties Characterization}

The sample used in this research is $\mathrm{ZnO}$ nanopowder synthesized by using the sol-gel method. Characterization of analyzed physical properties included the dimensions and morphology of $\mathrm{ZnO}$ nanopowder produced. The dimensions of ZnO nanopowder particles were performed by using XRD (X-ray diffraction) PanAnalytical, E’xpert Pro type. Determination of the particle size was obtained by using the following Scherrer equation [6]

$$
\begin{aligned}
& \mathrm{D}=\frac{\mathrm{K} \lambda}{(\beta \cos \theta)} \\
& \beta=\frac{\mathrm{FWHM} \times 2 \pi}{360^{\circ}}
\end{aligned}
$$

Where $\mathrm{K}$ is the Scherrer constant $(0.9-1), \lambda(\mathrm{m})$ is $\mathrm{x}$-ray wavelength used, $\beta$ is area of integral reflection (in radians $2 \theta$ ) located at $2 \theta$, and $\theta$ is scattering angle.

After that, morphology observation was performed by using scanning electron microscope (SEM) FEI Quanta 650 at the accelerating voltage of $10 \mathrm{kV}$, with the magnifications of 20,000x and 50,000x. This characterization is to observe the morphology of $\mathrm{ZnO}$ particles produced.

\subsection{Compression Test}

The compression test includes the green density of the tested material, the ability of $\mathrm{ZnO}$ nanopowder to be compressed by the compression pressures. As shown in Figure 2, the sample was compressed with the variations of loading of $500 \mathrm{~kg}, 1000 \mathrm{~kg}$, and $2000 \mathrm{~kg}$, also with variations of dwelling time of 30 seconds, 60 seconds, and 90 seconds, on a hydraulic press machine. 

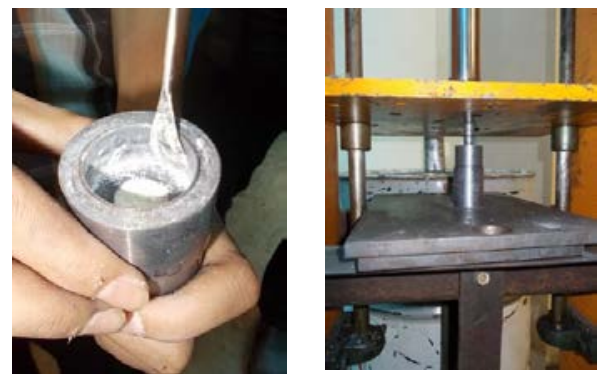

Figure 2. Compression test: preparation of powder on a jig (left); compression process (right)

\section{RESULTS AND DISCUSSION}

\subsection{Physical Properties}

The graph of XRD characterization result of $\mathrm{ZnO}$ nanopowder in Figure 3 shows the diffraction peaks that are identical to $\mathrm{ZnO}$ standard diffraction peaks. The graph shows that $\mathrm{ZnO}$ nanopowder sample is in the diffraction peaks in plots [100], [002], and [101] with Hexagonal Wurtzite structure.

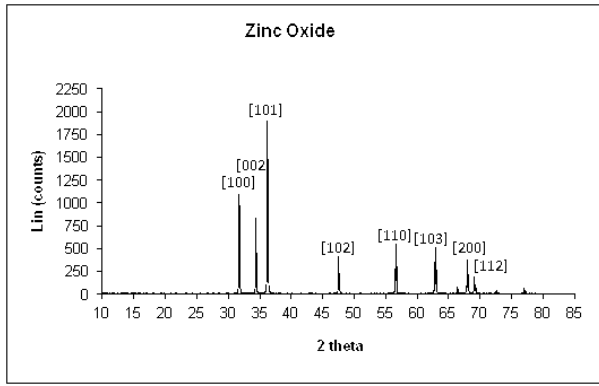

Figure 3. The graph of XRD characterization result

The peak of the diffraction shows a very strong peak intensity. This gives the sense that the ZnO nanopowder sample has a high crystallinity. The parameters of XRD characterization results are presented in Table 1.

Table 1. The Parameters of XRD Characterization

\begin{tabular}{lr}
\hline \multicolumn{1}{c}{ Parameters } & values \\
\hline Intensity (cps) & 1.890 \\
FWHM (2-theta $\left.{ }^{\circ}\right)$ & 0.113 \\
$\lambda(\AA)$ & 1.540 \\
$\theta\left({ }^{\circ}\right)$ & 18.120 \\
\hline
\end{tabular}

Using the equations 1 and 2, it can be calculated that the $\mathrm{ZnO}$ nanopowder sample produced has the particle size of $14.340 \mathrm{~nm}$.
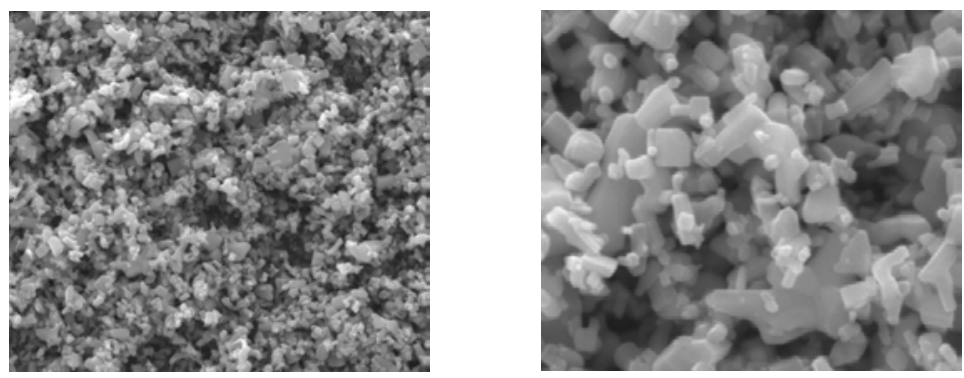

Figure 4. SEM observation of $\mathrm{ZnO}$ nanopowder (rectangles shows the area of next image with higher magnification)

Physical Properties and Compressive Strength of Zinc Oxide Nanopowder as a ... (Nanang Qosim) 
The morphology of the sample was observed by using SEM. The results are depicted in Figure 4. Figure 4 shows that the nanostructures of $\mathrm{ZnO}$ nanopowder are likely to look like nanorods types. This is due to the temperature and sintering time applied is quite good. The $\mathrm{ZnO}$ nanopowder produced has the right structure in terms of shape. Theoretically, the difference of temperature and sintering time will cause the difference in the structure of $\mathrm{ZnO}$ nanopowder. This is because $\mathrm{ZnO}$ is a versatile functional material that has various morphological groups such as nanocombs, nanorings, nanohelixes, nanosprings, nanobelts, nanowires, nanorods, nanocages, and so on. All of these unique classifications of nanostructures show that $\mathrm{ZnO}$ has a rich nanostructure in terms of structure and behavior.

\subsection{Compressive Strength}

All the results of compression test with the loading of 500, 1000, or $2000 \mathrm{~kg}$ show that the variation in compression loading took a very significant effect of increasing the average of green density. The improvement is theoretically due to the larger amount of compression load given, the higher the powder compressibility to increase. This can be identified from the thickness of sample resulted in compression.

In detail, as shown in Figure 5, at the dwelling time of 30 seconds, the loading of $500 \mathrm{~kg}$ took the green density of $3.112 \mathrm{~g} / \mathrm{cm}^{3}$, increased to 3.307 when the loading was increased $1000 \mathrm{~kg}$, then increased to 3.360 when the loading was increased $2000 \mathrm{~kg}$. At 60 seconds, the loading of $500 \mathrm{~kg}$ took the green density of $3.153,3.313$ for $100 \mathrm{~kg}$, and 3.372 for $2000 \mathrm{~kg}$. Furthermore, at 90 seconds, the loading of $500 \mathrm{~kg}$ took the green density of 3.245 . The loading of $1000 \mathrm{~kg}$ increased to 3.343 and 3.495 for $2000 \mathrm{~kg}$.

On the other hand, the difference in dwelling time also took a significant effect on the green density as shown in Figure 6. This means that the longer dwelling time applied, the higher the powder compressibility to increase. Based on the test results, in detail, at the loading of $500 \mathrm{~kg}$, the dwelling time of 30 seconds took the green density value of $3.112 \mathrm{~g} / \mathrm{cm} 3$, increased to 3.153 at 60 seconds, then increased to 3.245 at 90 seconds. Secondly, at a loading of $1000 \mathrm{~kg}$, the dwelling time of 30 seconds took the green density value of 3.307, 3.313 at 60 seconds, and 3.343 at 90 seconds. Last, when the loading on the hydraulic press machine was set at $2000 \mathrm{~kg}$, the green density value of sample was 3.360 at 30 seconds, increased to 3.372 at 60 seconds and increased again to 3.495 at 90 seconds.

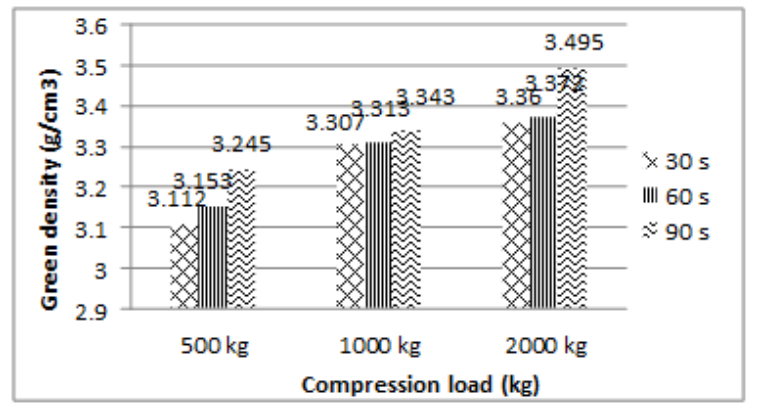

Figure 5. Effect of compression load on green density

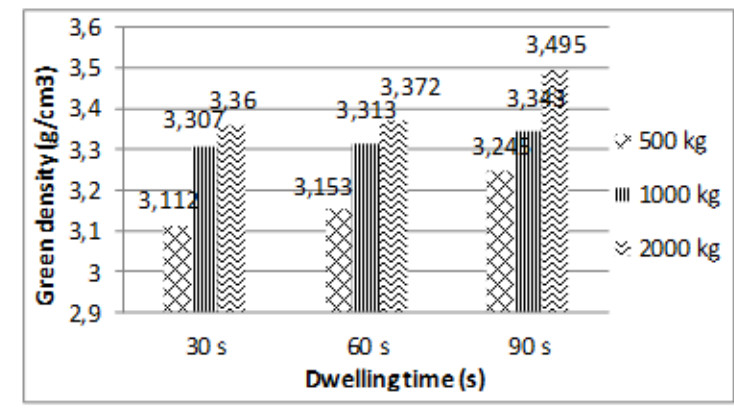

Figure 6. Effect of dwelling time on green density

This increases, theoretically, are caused by the dynamic behavior of compression rate when the compression dwelled for some seconds. So that, due to the dynamic loading, the green density would increase indicated by the smaller the thickness of the sample compressed.

\section{CONCLUSION}

The $\mathrm{ZnO}$ nanopowder analyzed has the particle size of $14.34 \mathrm{~nm}$ with the morphology classified as nanorods type. On the compression load of $500 \mathrm{~kg}$, the average of $\mathrm{ZnO}$ green density is $3.170 \mathrm{~g} / \mathrm{cm} 3$. This value experienced the increase of $4.763 \%$ when the load was set to $1000 \mathrm{~kg}$, and $7.539 \%$ at $2000 \mathrm{~kg}$. The dwelling time also took the same effect. At 30 seconds, the average of $\mathrm{ZnO}$ green density is $3.260 \mathrm{~g} / \mathrm{cm} 3$. This value experienced the increase of $0.583 \%$ at 60 seconds and $3.098 \%$ at 90 seconds. 


\section{ACKNOWLEDGEMENTS}

The authors would like to thank LPDP (Indonesian Endowment Fund for Education), Ministry of Finance, Republic of Indonesia, for scholarship funding “Beasiswa Pendidikan Indonesia LPDP”.

\section{REFERENCES}

[1] E. Rodríguez-Farre, E. Testai, E. Bruzell, W. De Jong, G. Schmalz, M. Thomsen, et al., "The safety of dental amalgam and alternative dental restoration materials for patients and users," Regulatory toxicology and pharmacology: RTP, vol. 79, pp. 108-109, 2016.

[2] T. Berniyanti and N. Hariyani, "Side effects of mercury in dental amalgam," Dental Journal (Majalah Kedokteran Gigi), vol. 41, pp. 30-34, 2008.

[3] R. A. Bernhoft, "Mercury toxicity and treatment: a review of the literature," Journal of environmental and public health, vol. 2012, 2012.

[4] Z. L. Wang, "Zinc oxide nanostructures: growth, properties and applications," Journal of Physics: Condensed Matter, vol. 16, p. R829, 2004.

[5] P. Bedi and A. Kaur, "An overview on uses of zinc oxide nanoparticles," World Journal of Pharmacy and Pharmaceutical Sciences, vol. 4, pp. 1177-1196, 2015.

[6] D.-M. Smilgies, "Scherrer grain-size analysis adapted to grazing-incidence scattering with area detectors. Erratum," Journal of Applied Crystallography, vol. 46, pp. 286-286, 2013. 